Int. J. Electrochem. Sci., 14 (2019) 1040 - 1068

\title{
Synthesis of Polymers Containing Residues of Biogenic Amino Acid Methionine, Methionine Sulfoxide and Methionine Sulfone and Their Application as Inhibitors of Mild Steel Corrosion
}

\author{
Mohammad Abu Jafar Mazumder \\ Chemistry Department, King Fahd University of Petroleum and Minerals, Dhahran 31261, Saudi \\ Arabia \\ E-mail: jafar@kfupm.edu.sa
}

doi: $10.20964 / 2019.01 .83$

Received: 25 November 2017 / Accepted: 2 November 2018 / Published: 30 November 2018

\begin{abstract}
Ethyl ester hydrochloride of L-methionine I was converted to its $N, N$-diallyl derivative II which upon treatment with $\mathrm{HCl}$ led to $N, N$-diallyl methionine ethyl ester hydrochloride III. Cationic monomer III underwent cyclopolymerization to give polymer sulfide IV, embedded with five-membered pyrrolidine rings, which upon oxidation in the presence of 1 and 2 equivalents of $\mathrm{H}_{2} \mathrm{O}_{2}$ afforded polymer sulfoxide $\mathbf{V}$ and polymer sulfone VI, respectively. The thermal stability, intrinsic viscosity and critical micelle concentrations of these polymers were determined. The inhibition efficiency obtained from gravimetric weight loss, were corroborated by the findings of potentiodynamic polarization and electrochemical impedance spectroscopy. The critical micelle concentration of the polymers IV-VI has been determined to be $\approx 6 \mathrm{ppm}$. At a concentration of $\approx 5.5 \mathrm{ppm}$ in $1.0 \mathrm{M} \mathrm{HCl}$, the polymers IV-VI imparted remarkable corrosion inhibition efficiency (IE) of 86, 87 and $83 \%$, respectively; while in the presence of $22.8 \mathrm{ppm}$ of polymer sulfoxide $\mathbf{V}$, an IE of $97 \%$ was achieved. The potentiodynamic polarization and EIS studies suggested that the polymer chains form a protective layer and quarantine the metal surface from the corrosive environment. The XPS and SEM-EDX supported the adsorption and the film forming ability of the studied polymer compounds on the metal surface.
\end{abstract}

Keywords: Cyclopolymerization; Methionine sulfide; Methionine sulfoxide; Methionine sulfone; Mild steel; Corrosion inhibition.

\section{$\underline{\text { FULL TEXT }}$}

(C) 2019 The Authors. Published by ESG (www.electrochemsci.org). This article is an open access article distributed under the terms and conditions of the Creative Commons Attribution license (http://creativecommons.org/licenses/by/4.0/). 